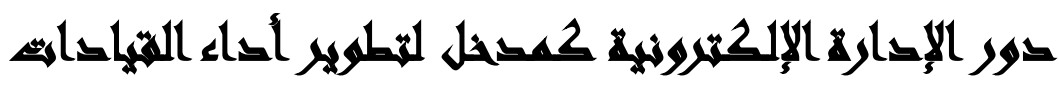

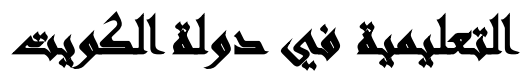

[11]

$$
\text { وزارة التربية، دولة الكوض المطيري }
$$

\section{المسرخليس}

هدفت الدراسة التعرف على دور الإدارة الإككترونية في تطوير أداء القيادات التعليمية

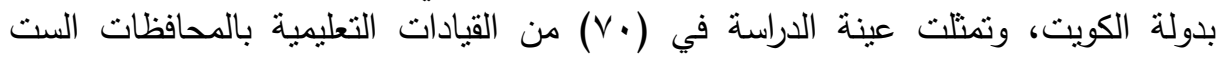
(محافظة العاصمة، محافظة الفروانية، محافظة الجهراء، محافظة الأحمدي، محافية فئة بالفة مبارك الكبير ، محافظة حولي) بدولة الكويت، واستخدمت الدراسة المنهج الوصفي التحليلي. نتائج الدراسة: • أظطهرت النتائج وجود اختلافات فى الآراء بنسبة بلغت 11.14\% وهي أقل من النسبة

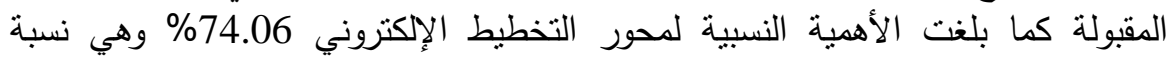

• أفهرت، النائج وجود اختلافات في الآراء بنسبة بلغت 9.78\% وهي أقل من النسبة

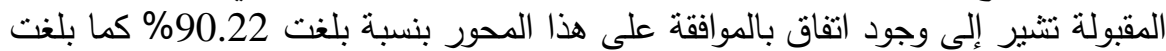

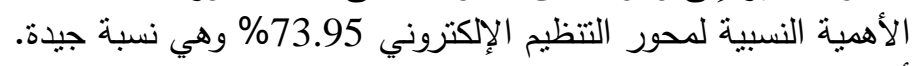
• أظهرت النتائج وجود اختلافات فئ الآراء بنسبة بلغت

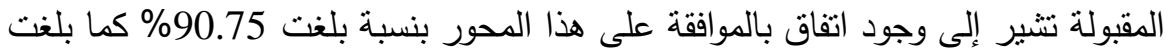

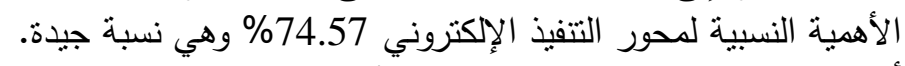

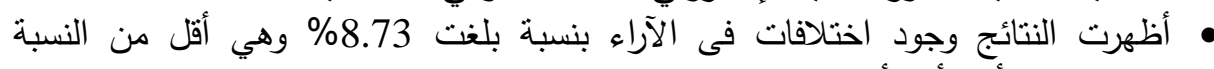

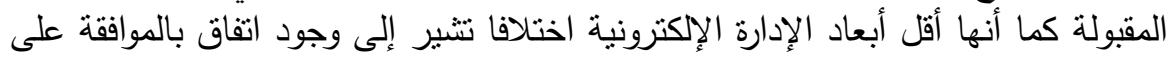

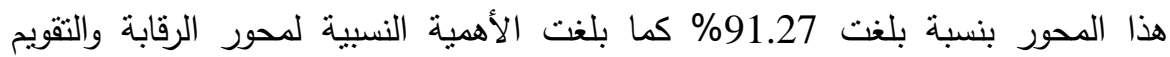

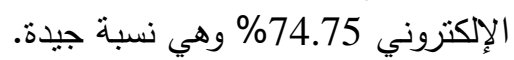
الكلمات المفتاحية: دور - الإدارة الإلكترونية - تطوية وهير أداء - القيادات التعليمية. 


\section{$\sin$}

تُعد الإدارة الإلكترونية من أهم مداخل التطوير للقيادات التعليمية حيث تستخدم فيها التقنيات الحديثة متل الكمبيوتز، وشبكة الاتصالات المحلية الإنترانت، والثبكة العالمية

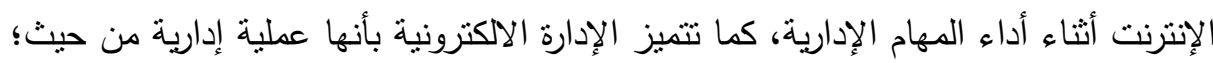

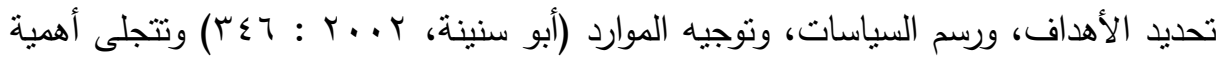

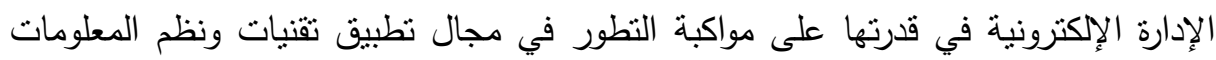

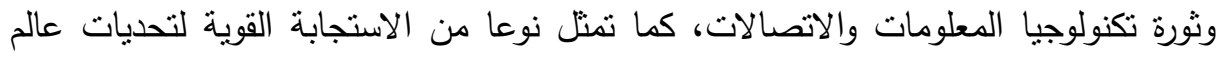
القرن الحادي والعشرين الذي تختصر العولمة والفضاء الرقمي وافتصاديات المعلومات والمعرفة وثورة الإنترنت وشبكة المعلومات العالمية كل متغيراته وحركة اتجاهاته.

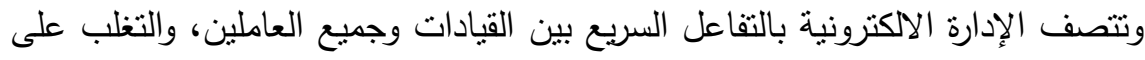
حاجز الزمن والمكان، وانخفاض الكلفة والسرعة الفائقة والعمل عن بعد وبلا حدود، وتركز

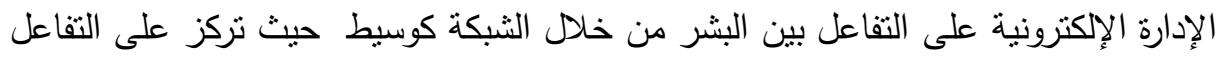

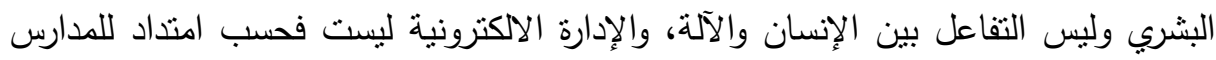

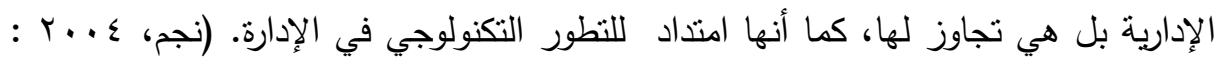

ويُعد مدخل الإدارة الإلكترونية بالمؤسسات التعليمية أحد الاتجاهات الحديثة التي تساعد

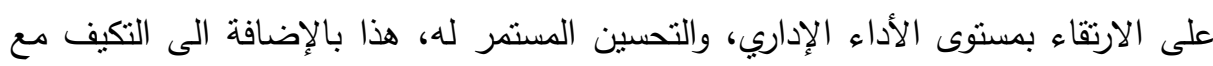

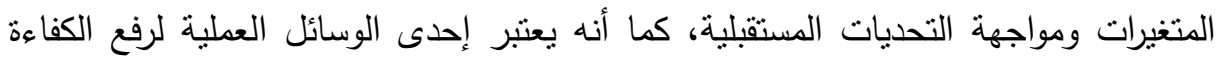

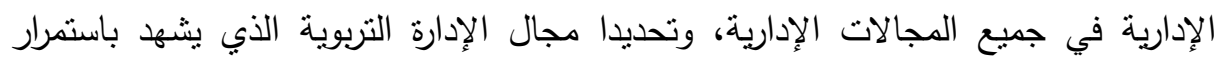

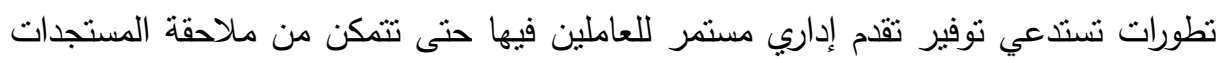

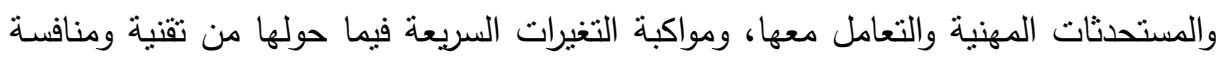
وفي الممارسـات الإداريـة نفسها. 
وتتشير الأدبيات المعاصرة إلى أن العصر الحالي بعتبر عصر المعلومات وعصر الثروة والقوة المتنظة بغزارة المعلومات والمعرفة والقدرة على (Information Age) تكوينها وتراكمها وتقاسمها واستخدامها بكفاءة عالية، وبطلق كثثر من العلماء المتخصصين

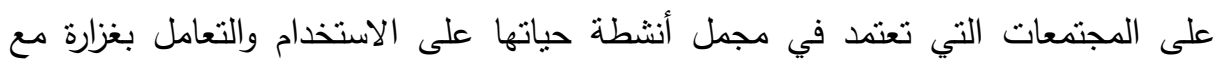

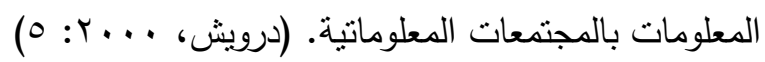

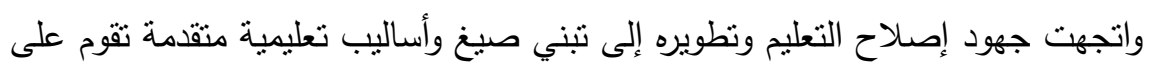
فلسفة جديدة للتعليم مرتكزاتها: التعليم الإكتروني والإدارة الإككترونية، مما بعد ثورة على ولى النظم التعليمية التقليدية، حيث استلزم تطوير الصيخ التقليدية وتطبيق صيغ حديثة نتبنى أساليب

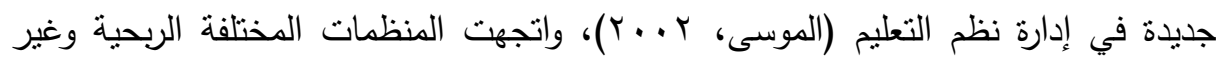

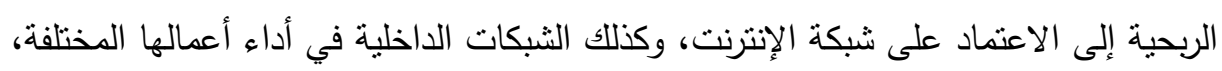

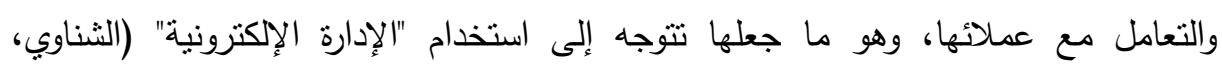

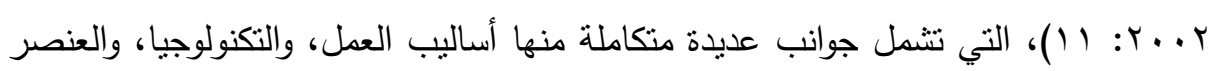

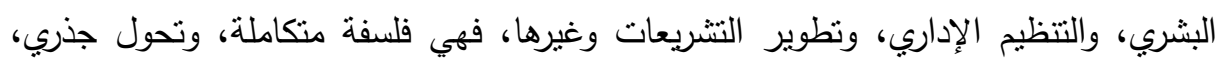

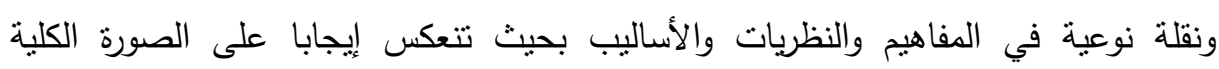

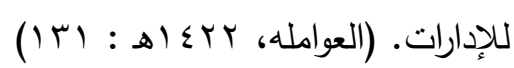

وبالتالي فإن الإدارة الإكترونية متجاوز بكثثر مفهوم الميكنة الخاصة بإدارات العمل

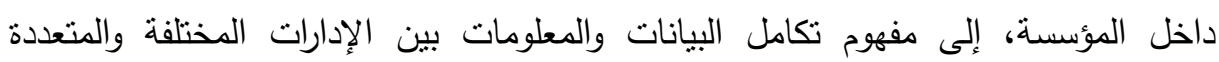
واستخدام تلك البيانات والمعلومات في توجيه سياسة وإجراءات عمل المؤسسة نحو تحقيق

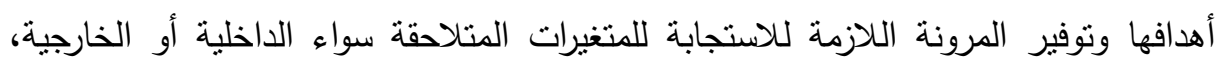
وتتشمل جميع مكونات الإدارة من تخطيط وتتفيذ ومتابعة وتقييم وتحفيز ؛ إلا إنها تتميز بقدرتها على توليد المعرفة بصورة مستمرة وتوظيفها من أجل تحقيق الأهداف، وتعتمد على تطوير

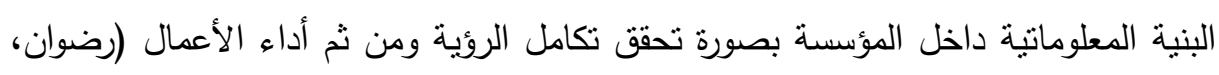

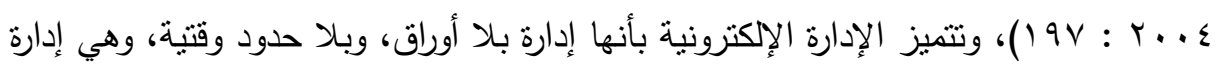


بلا مبان تقليدية؛ فلا حاجة إلى الغرف والمكاتب والدواليب الكثيرة لحفظ الأوراق. (سيد، $(r v-r q:$ : r..

كما تسهم الإدارة الإلكترونية في تحقيق جملة من الفوائد للمؤسسات التعليمية من أبرزها؛

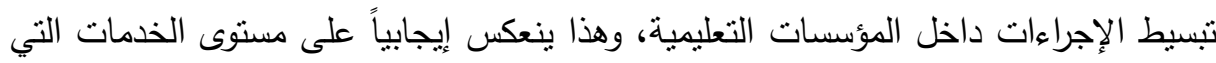

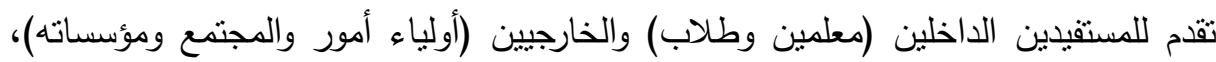

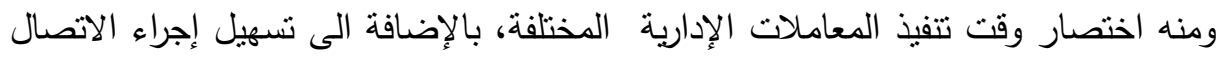
بين الإدارات التعليمية، وكذلك مع المؤسسات الأخرى، وضمان الدقة والموضوعية في إنجاز

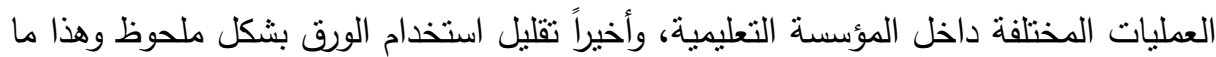

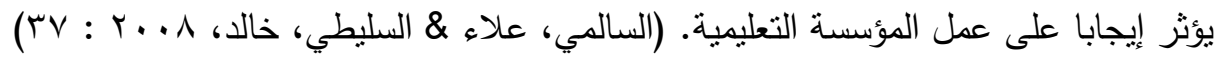

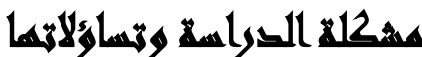

في ضوء ما سبق، وما أفرزته نتائج الدراسات السابقة لدور وأهمية الإدارة الإلكترونية في تطوير أداء القيادات التعليمية، حيث إن الأخذ بالأساليب الحديثة والاتجاهات العالمية المعاصرة في الفكر الإداري المعاصر يمكن أن يساعد على تطوير الأداء، والمساهمة في حل المشكلات، وتلافي نواحي الخلل في وظائف المؤسسات التعليمية التي ينتج عنها العديد من السلبيات، والتي تحتاج المزيد من المتابعة باستخدام الإدارة الإلكترونية، (السميري، 9 ... ؟ V

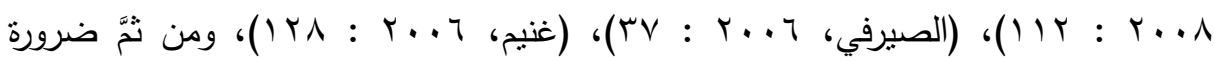
التعرف على مستويات تطبيقها من وجهة نظر القيادات التعليمية بدولة الكويت والكثف عن مشكلات تطبيقها لتفعيل دورها كمدخل لتطوير أداء القيادات التعليمية في دولة الكويت. وتأسيسا على ما سبق يمكن صياغة مشكلة الدراسة في السؤال الرئيس التالي: ما دور الإدارة الإلكترونية في تطوير أداء القيادات التعليمية في دولة الكويت؟ ويتفرع من هذا السؤال الأسئلة الفرعية التالية:

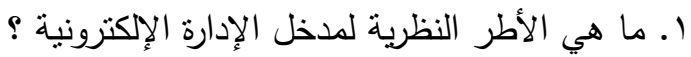


r. ما واقع تطبيق الإدارة الإلكترونية لدى القيادات التعليمية في دولة الكويت؟

\section{أهمالهي التوراسة}

تهدف الدراسة التعرف على دور الإدارة الإكترونية في تطوير أداء القيادات التعليمية

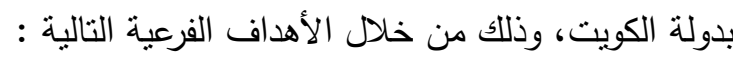
1-التعرف على الأطر النظرية لمدخل الإدارة الإلكترونية. r- الكثف عن واقع تطبيق مدخل الإدارة الإكترونية لدى القيادات التعليمية في دولة الكويت.

\section{أهمي التصواسم}

ا. يفيد التعرف على الأطر النظرية لمدخل الإدارة الإككترونية في التعرف على الأهمية التي يلعبها هذا المدخل في تطوير أداء القيادات التعليمية في دولة الكويت.

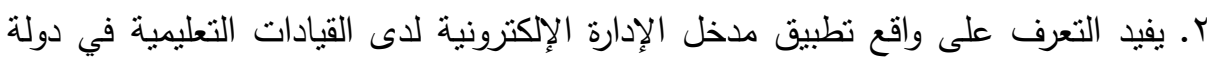

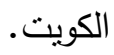

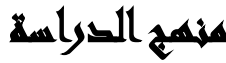

تنتخدم الدراسة المنهج الوصفي التحليلي لتفسير ووصف الظروف والعلاقات التى توجد

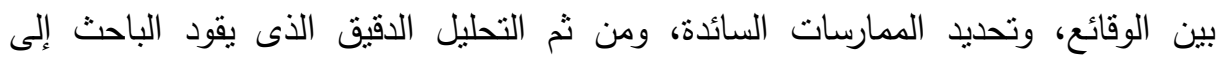

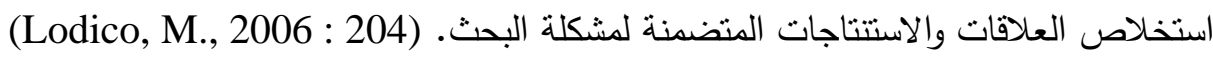

\section{لوضور القراسمة}

حدود موضوعية: الإدارة الإكترونية - تطوير أداء القيادات التعليمية. حدود مكانية: المناطق النعليمية بالمحافظات الست (محافظة العاصمة، محافظة الفروانية،

محافظة الجهراء، محافظة الأحمدي، محافظة مبارك الكبير ، محافظة حولي) بدولة الكويت. حدود بشرية: تكونت الحدود البشرية من (•V) القيادات التعليمية بالمحافظات الست بدولة

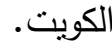




\section{إجزاءايه السراسها}

تتتاول الدراسة في هذا الجزء منهجية الدراسة وصفًا للمنهج المتبع من حيث أسلوب الدراسة المستخدم، ومجتمع وعينة الدراسة، وصدق وثبات الاستبيان، بالإضافة إلى تحديد

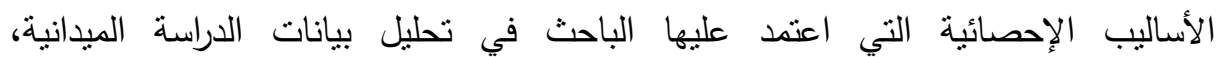
ويستعرضها الباحث على النحو التالي:

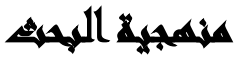

1 - أسلوب الدراسة: بناءً على طبيعة الدراسة والأهداف التي تسعى إلى تحقيقها فقد استخدم الباحث المنهج الوصفي التحليلي، والذي يعتمد على دراسة الظاهرة كما توجد في

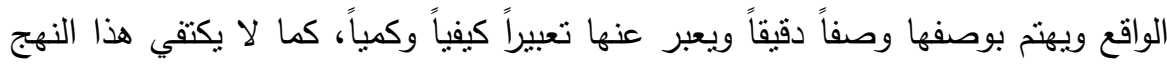

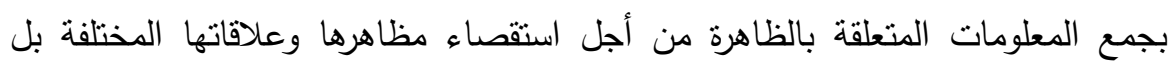
يتعداه إلى التحليل والربط والتقسير للوصول إلى استتناجات يبنى عليها التصور المقترح بحيث يزيدها رصد المعرفة الموضوعية، وقد نم الاعتماد على أسلوب الدراسة النظرية

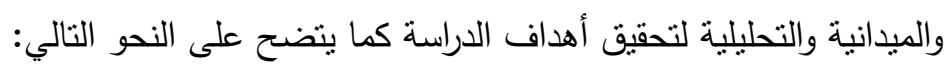
أ- الاراسة النظرية: اعتمد الباحث في تكوين الإطار النظري للاراسة على المجلات العلمية الهاتية والدوريات والأبحاث العلمية المتخصصة المنشورة وغير المنشورة والكتب العربية والأجنبية والتي تتاولت موضوع الدراسة؛ وأي جانب من جوانبه. ب- الدراسة الميدانية: نم الاعتماد هنا على أسلوب قوائم الاسنتيان لجمع البيانات الأولية

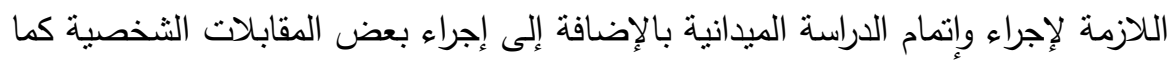

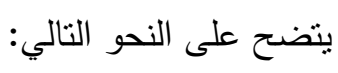

• قوائم الاستبيان: تعتبر استمارة الاستبيان أداة ملائمة بشكل كبير في تقصي الآراء ووجهات النظر حول مسألة أو قضية ما، وقد تم استخدام استمارة الاستبيان كأداة رئيسية للحصول على البيانات الأولية من مجتمع الدراسة، وتم تصميم استمارة استبيان في ضواء

$$
\text { أهداف الدراسة إلى أفراد العينة. }
$$


• المقابلات الثخصية: اعتمد الباحث على المقابلات الثخصية عند نوزيع استمارة الاستنيان، وذلك للإجابة على جملة من الاستفسارات التي قد ترد من المستقصى منهم

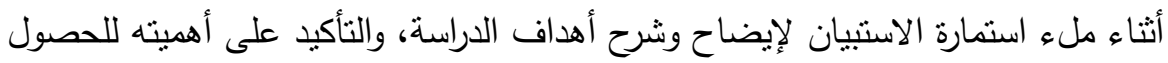

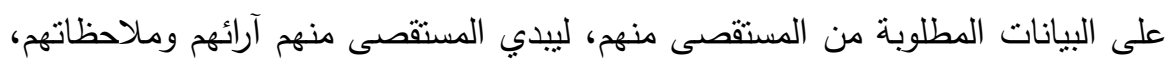
كذلك للحصول على بعض المعلومات التي لا يمكن الحصول عليها بواسطة الاستبيان.

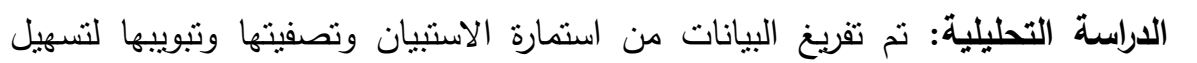
عملية تحليلها، وذلك لاستخلاص النتائج والمؤشرات منها حول موضوع الدراسة باستخدام وسائل إحصائية مناسبة تتفق مع الفروض الأساسية الخاصة بالدراسة. r - مجتمع الدراسة: مجتمع الدراسة يعرف بأنه جميع مفردات الظاهرة التي يدرسها الباحث، بذلك فإن مجتمع الدراسة هو جميع الأفراد الذين يكونون موضع مشكلة الدراسة، بناءً على مشكلة الدراسة وأهدافها.

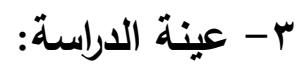
جدول رقم(1): مجتمع وعينة الدراسة والاستمارات الموزعة

\begin{tabular}{|c|c|c|c|c|}
\hline الاستمارات القابلة & المستردة والمستبارات غير & الاستمارات & عينة الدراسة & الاستمارات الموزعة \\
\hline$V$. & $V$ & $\vee$. & $V V$ & $V V$ \\
\hline
\end{tabular}

ع - أداة الدراسة: تكونت استمارة الاستبيان من المحاور التالية: 1- التخطيط الإلكتروني ويشتمل على (· ( ) فقرة. r- التنظيم الإلكتروني ويشتنمل على (T (1) فقرة.

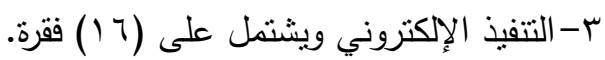

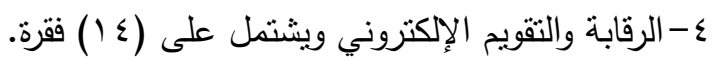
وتم استخدام مقياس ليكرت الخماسي لقياس استجابات المبحوثين لفقرات الاستبانة حسب الإب

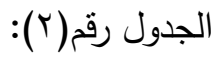




\begin{tabular}{|c|c|c|c|c|c|}
\hline \multicolumn{6}{|c|}{ جدول روم(Y): درجات مقياس ليكرت الخماسي } \\
\hline غير موافق تماماً & غير موافق & إلى حد ما & موافق & موافق تماماً & الاستجابة \\
\hline 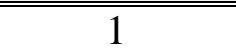 & 2 & 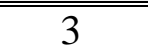 & 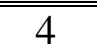 & 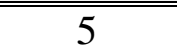 & 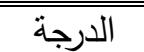 \\
\hline
\end{tabular}

وبذلك يكون الوزن النسبي لكل درجة استجابة في هذه الحالة هو (20\%) يتناسب مع

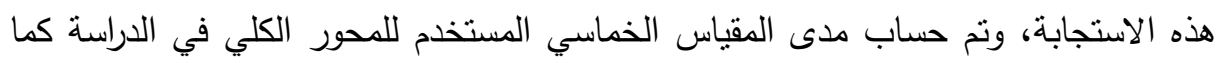

$$
\begin{aligned}
& \text { يلي: } \\
& \text { حساب المدى = (0 - 1 ) / }
\end{aligned}
$$

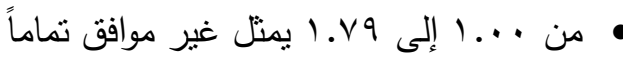

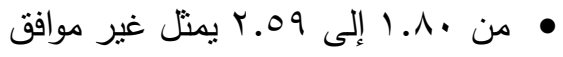

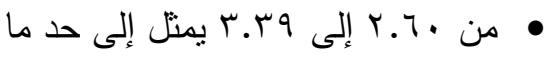

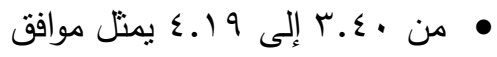

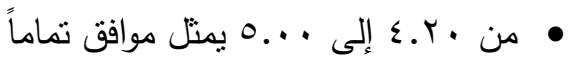

ه- صدق الاستبيان: يقصد بصدق الاستبيان أن تقيس أسئلة الاستبيان فيما وضعت

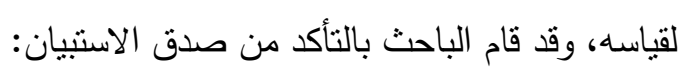

أ-صدق المحكمين "الصدق الظاهري": قبل اعتماد استمارة الاستبيان من قبل الباحث، ما تضمنته من أسئلة كان لا بد من اختبار صدق المقياس وقياس ثنات استمارة الاستنيان. * اختبار صدق المقياس: الأداة الصادقة هي الأداة التي تقبس ما صمدت من أجل فئ فياسل والمقصود بصدق الأداة هو صدق النتائج التي يتم جمعها، أو التوصل إليها باستخدام تلك التك الأداة، من أجل اختبار صدق استمارة الاستبيان فقد تم عرض استمارة الاستبيان

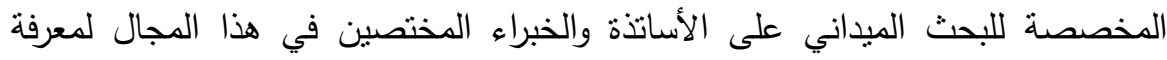
آراءهم بمدى وضوح وترابط فقرات الاستمارة ونوعية الأسئلة وتوافقها مع موضوع الدراسة.

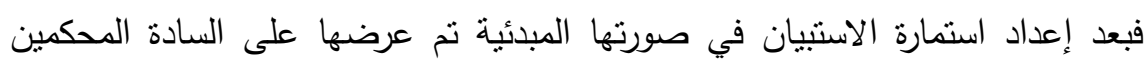
وذلك للتحقيق من: 
1- إناسبة الأداة للهدف الذي صممت من أجله. r-سلامة صياغة المفردات ووضوحها. ب-حذف أو إضافة ما براه السادة المحكمين مناسبًا من مفردات أو تعديلها، في ضودة ضوداء الملاحظات التي أبداها السادة المحكمين أجريت التعديلات اللازمة لتأخذ الاستمارة صورتها النهائية.

أولًا: الصدق والثبات لأبعاد الاستبانة: معامل ثبات ألفا كرونباخ Reliability: ويقصد به استقرار المقياس وعدم تناقضه مع نفسه، أى أنه يعطى نفس النتائج إذا أعيد تطبيقه على نفس العينة ولإجراء اختبار الثبات لأسئلة الاستبانة نستخدم إحدى معاملات الثبات متل معامل ألفا كرونباخ. ومعامل الثبات بأخذ قيم

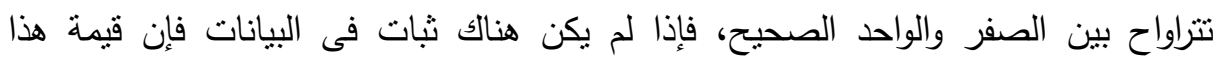
المعامل نساوى الصفر والعكس صحيح حيث إذا كان هناك ثبات تام تكون قيمة المعامل

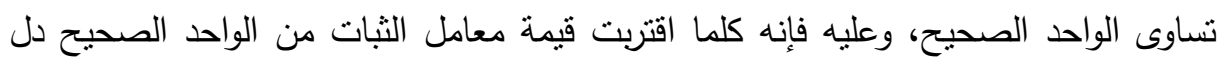
ذلك على وجود ثبات فى البيانات (استجابات أفراد العينة) ويقصد بثبات أداة القياس أن يعطي النتائج نفسها إذا أعيد نطبيق الاسنبانة على نفس أنسات

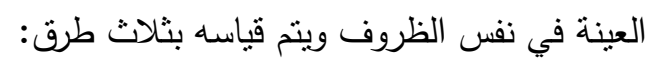

1-الطريقة الأولى: الاختبار وإعادة الاختبار يتم في هذه الطريقة تطبيق الاستبانة على عينه استطلاعية مرتين بينهما فارق زمني مدته أسبوعان ثم حساب معامل الارتباط بين إجابات

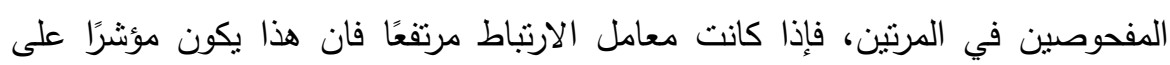

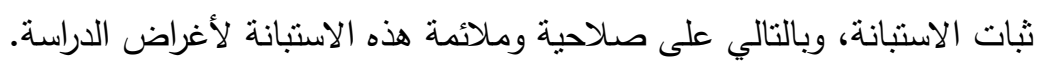

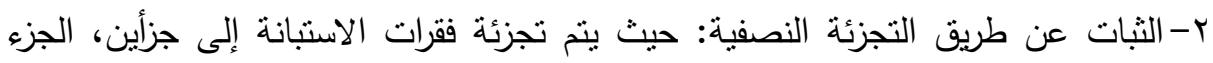

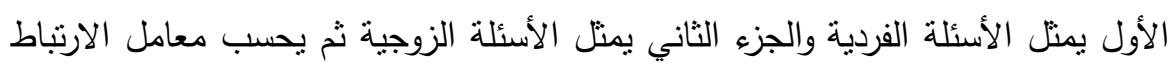

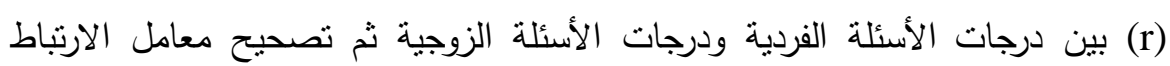
بمعادلة بيرسون براون. 
معامل ثبات كرونياخ الفا.

معامل الصدق معلقيات :Validity ويقصد به أن المقياس يقيس ما وضع لقياسه ويمكن حسابه رياضيا من خلال الجذر التربيعي لمعامل الثبات.

يتم حساب معامل ثبات ألفا كرونباخ باستخدام برنامج (22) جدول رقم(ץ): معاملات الثبات والصدق لمحاور الدراسة

\begin{tabular}{|c|c|c|c|}
\hline معامل الصدق & معامل الثبات & عدد الفقرات & محاور الاراسة \\
\hline .942 & .888 & 10 & التخطيط الإكتروني \\
\hline .956 & .914 & 16 & التتظيم الإلكتروني \\
\hline .925 & .856 & 16 & النتفيذ الإلكتروني \\
\hline .922 & .850 & 14 & الرقابة والتقويم الإككتروني \\
\hline .982 & .964 & 56 & الإدارة الإلكترونية \\
\hline
\end{tabular}

ويتضح من الجدول السابق قيم معاملات الثبات ألفا كرونباخ لأبعاد الاستبانة وكانت

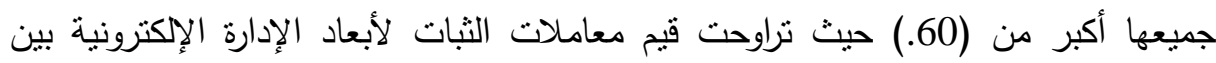
(850. - 914.) وهي نسب مرتفعة تعطى ثقة لدى الباحث فى النتائج التالية، كما تبين وجود صدق عال لهذه المحاور فقد كانت قيم الصدق جميعها مرتفعة حيث تراوحت قيم معاملات

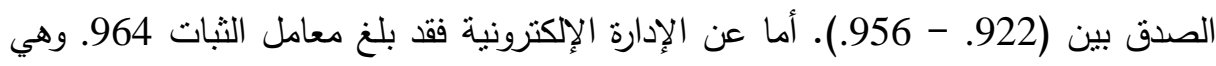

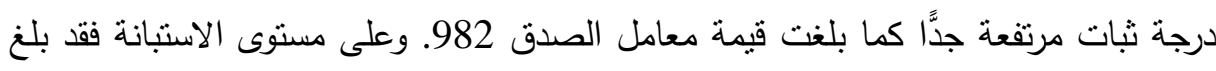
معامل الثبات (954.).

الاتساق الداظلمِن حيث ينم قياس مدى ارتباط وتمثنل الفقرة للحور الرئيسى له فإذا كان

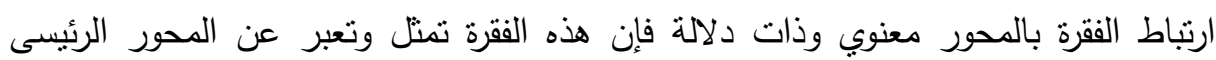
وبشكل جيد. الصدق Validity: الصدق بيساطة هو أن نقيس أسئلة الاستبانة أو الاختبار ما وضعت لقياسه أب يقيس فعلا الوظيفة التي يفترض أنه يقيسها. 
فالاختبار الصادق هو الذي يقيس الجانب الذي أعد من أجل قياسه ومن أنواع الصدق

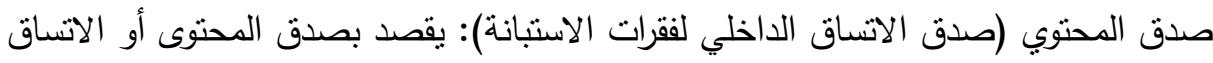
الداخلي مدى اتساق كل فقرة من فقرات الإستبانة مع المجال الذي نتتمي إليه هذه الفقرة. ويمكن حساب الاتساق الداخلي للإستبانة وذلك من خلال حساب معاملات الارتباط بين

كل فقرة من فقرات مجالات الإستبانة والدرجة الكلية للمجال نفسه . المحور الأول: التخطيط الإكتروني: جدول رقم(؛): الاتساق الداخلى لفقرات محور التخطيط الإكتروني الإكتي

\begin{tabular}{|c|c|c|}
\hline 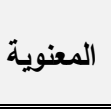 & معامل ارتباط & التخطيط الإلكتروني \\
\hline .000 & $.684 * *$ & يؤدي استخدام الإدارة الإلكترونية في التخفيف من الأعباء الإدارية المختلفة. \\
\hline .000 & $.699 * *$ & تعمل الإدارة الإككرونية على تقليل كلفة إجراءات التخطيط الإداري. \\
\hline .000 & $.483 * *$ & يُسركل استخدام الإدارة الإلكترونية مواكبة المتغيرات والمستجدات الإدارية العالمية. \\
\hline .000 & $.373 * *$ & تُساهم الإدارة الإلكترونية في تطوير نظم التخطيط الإداري. \\
\hline .000 & $.538 * *$ & تُساعد الإدارة الإككترونية في إكساب الإداريين العديد من الخبرات الإدارية. \\
\hline .000 & $.413 * *$ & تُساهم الإدارة الإلكترونية في توفير الخطط الإدارية البديلة عند الحاجة. \\
\hline .000 & $.450 * *$ & يؤدي استخدام الإدارة الإككترونية في تطبيق مفهوم التخطبط المتكامل. \\
\hline .000 & $.666^{* *}$ & تُشكل أفضل الإدارة الإلكترونية في وضع خطط توظيف الموارد البشرية والمادية \\
\hline .000 & $.655^{* *}$ & تُشاهم الإدارة الإلكترونية في إثثراك جميع الأطراف في التخطيط الإستراتيجي. \\
\hline .000 & $.719 * *$ & تُساعد الإدارة الإلكترونية في الحد من مشكلات التخطبط. \\
\hline
\end{tabular}

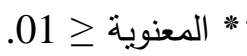

يتضح من الجدول السابق أن هناك ارتباط ذات دلالة إحصائية بين فقرات التخطيط الإلكتروني والبعد الكلي للتخطبط الإلكتروني عند مستوى ثقة (99.) تراوحت قيم الارنباط بين

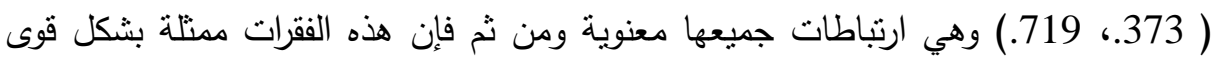
للاحور الرئيسى التخطيط الإلكتروني وتقيس الغرض المبات المرجو منه. 
المحور الثانى: التنظيم الإكتروني : جدول رقم(ه): الاتساق الداخلى لفقرات محور التظيم الإلكتروني

\begin{tabular}{|c|c|c|}
\hline 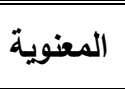 & سبيرمان & التظظيم الإكتروني \\
\hline .000 & $.422 * *$ & وُكُاعد الإدارة الإلكترونية في الحصول على المعلومات في أي وقت \\
\hline .000 & $.512 * *$ & توفر الإدارة الإلكترونية في توفير نظام أرشفة إلكترونية لدختلف \\
\hline .000 & $.497 * *$ & تُساهم الإدارة الإككترونية في توفير الوقت والمال والجهد. \\
\hline .000 & $651^{* *}$ & توفر الإدارة الإلكترونية عناء الانتقال عبر الإدارات لإنجاز المعاملات. \\
\hline .000 & $348 * *$ & تُُساهم الإدارة الإلكترونية في تنظيم عملية نسجيل المواد الدراسية. \\
\hline .000 & $.431 * *$ & تعمل الإدارية. الإلكترونية على تسهيل عملية التوجيه لمختلف الأطراف \\
\hline .000 & .523 & تُساهم: الإدارة الإلكترونية في تأمين التواصل بين مختلف العناصر \\
\hline . 000 & $.625^{*}$ & فُسى وقد الإدارة الإلكترونية في استيعاب أكبر عدد ممكن من المستقيدين \\
\hline .000 & $.337 * *$ & تساعد الإدارة الإلكترونية في كسر حاجز الروتين في إجراء المعاملات \\
\hline .000 & $.597 * *$ & تُساهم الإدارة الإككترونية في رفع مستوى تطبيق إدارة شؤون الطلبة. \\
\hline .000 & $.598 * *$ & تُشساهية. الإدارة الإككترونية في توفير فرص الإطلاع على جداول المواد \\
\hline .000 & .52 & تساعد الإدارة الإلكترونية في تتظيم الاجتماعات إلكترونيًا. \\
\hline .000 & $.545 * *$ & تساهم الإدارة الإلكترونية في إيجاد بيئة تتظيمية تتسم بالدقة. \\
\hline . 000 & .471 & تساعد الإدارة الإلكترونية في توفير مبدأ الخصوصية لدى مختلف \\
\hline .000 & $.469 * *$ & إلكترونيًا. الإدارة الإلكترونية في تحقيق التواصل مع أولياء أمور الطلاب \\
\hline .001 & $.545^{* *}$ & داخل النظام الإلكترونى الإلكترونية لكل طالب رقم تعريفي إلكتروني خاص بحالته \\
\hline
\end{tabular}


يتضح من الجدول السابق أن هناك ارتباط ذات دلالة إحصائية بين فقرات التنظيم الإلكتروني والبعد الكلي للتنظيم الإلكتروني عند مستوى نقة (99.) تراوحت قيم الارتباط بين

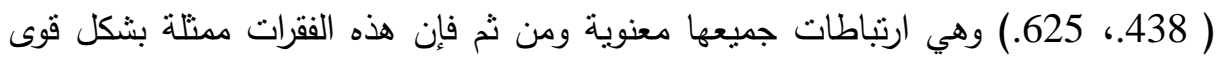

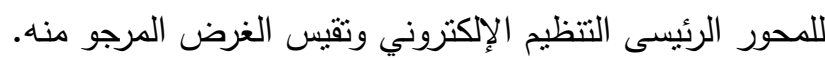

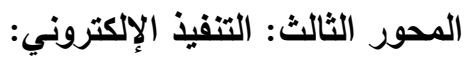
جدول رقم(†): الاتساق الداخلى لفقرات محور التنفيذ الإكتروني

\begin{tabular}{|c|c|c|}
\hline 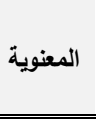 & سبيرماط & التنفيذ الإكتروني \\
\hline .024 & $.338 * *$ & تعمل الإدارة الإلكترونية على توفير البيانات لدى جميع المستفيدين من خدمات الوزارة. \\
\hline .000 & $.526^{* *}$ & تُساعد الإدارة الإلكترونية في التخلص من النظام البيروقراطي في إنجاز المعاملات. \\
\hline .002 & $.256^{* *}$ & تساهم الإدارة الإلكترونية في تأدية الوزارة لوظيفتها التربوية والمجتمعية. \\
\hline .000 & $.535^{* *}$ & الجداعدة الإدارة الإلكترونية القيادات على الدئ الأستجابة للمستجدات والإبداع وتجريب الأفكار والأساليب \\
\hline .000 & $.613^{* *}$ & تُساعد الإدارة الإككترونية في تتفيذ العديد من الخطط الإدارية بسهولة ويسر. \\
\hline .000 & $.415^{* * *}$ & تعمل الإدارة الإككترونية على تقديم المعلومات بشكل دقيق وسليم. \\
\hline .000 & $.538 * *$ & يؤدي استخدام الإدارة الإلكترونية في دعم القيادات لتحقيق مراكز متقدمة في الإدارة الإكترونية. \\
\hline .000 & $.508 * *$ & تساعد الإدارة الإكترونية في الاستغلال الأمتل لمصادر المطلومات المتاحة. \\
\hline .000 & $.506^{* *}$ & تساهم الإدارة الإكترونية في تسهيل عملية الحصول على الوثائق والمعاملات الرسمية. \\
\hline .000 & $.483 * *$ & تُساعد الإدارة الإلكترونية في تحسين الأداء الإداري في جميع التعاملات مع أولياء أمور الطلاب. \\
\hline .000 & $.537 * *$ & تعمل الإدارة الإلكترونية على الحد من تأثير العلاقات الثخصبة في إنهاء المعاملات. \\
\hline .000 & $.630 * *$ & الندوات، الإدارة الإكترونية للإداريين والمعلمين الإطلاع على مصادر المعلومات العالمية (الدورات، \\
\hline .000 & $.731 * *$ & تساعد الإدارة الإككترونية في تحقيق مبدأ الثفافية في تقديم الخدمات. \\
\hline .000 & $.397 * *$ & توفر الإدارة الإلكترونية الكثير من المرونة والسرعة في تقديم الخدمات. \\
\hline .000 & $.398 * *$ & 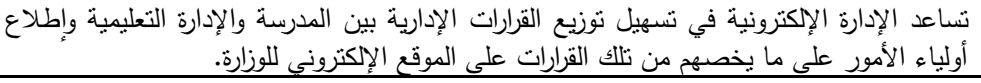 \\
\hline .006 & $.330 * *$ & تساهم الإدارة الإككترونية في سرعة تنفيذ القرارات الإدارية. \\
\hline
\end{tabular}


يتضح من الجدول السابق أن هناك ارتباط ذات دلالة إحصائية بين فقرات التتفيذ الإككتروني والبعد الكلي للتنفيذ الإلكتروني عند مستوى نقة (99.) تراوحت قيم الارتباط بين

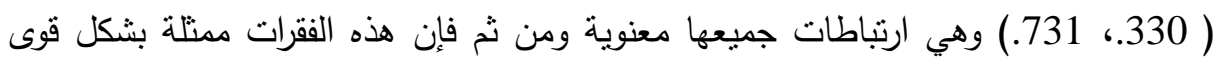

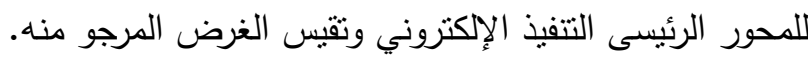
المحور الرابع: الرقابة والتقويم الإكتروني: جدول رقم(V): الاتساق الداخلى لفقرات محور الرقابة والتقويم الإكتروني الإنكروني

\begin{tabular}{|c|c|c|}
\hline 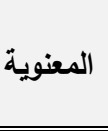 & 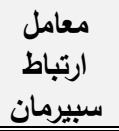 & الرقابة والتقويم الإكتروني \\
\hline .000 & $.429 * *$ & تُساهم الإدارة الإلكترونية في تطبيق نظام تدقيق مالي منطور . \\
\hline .000 & $.384 * *$ & تُساعد الإدارة الإلكترونية في منابعة الخطط والأعمال اليومية. \\
\hline .002 & $.583 * *$ & تزود الإدارة الإككترونية القبادات التعليمية بالتقارير والبيانات الإحصائية. \\
\hline .000 & $.662 * *$ & تُسالوزارة. الإدارة الإلكترونية في توفير نظام رقابي إلكتروني وفقًا للوائح والتعليمات \\
\hline .000 & $.454 * *$ & تُساهم الإدارة الإلكترونية في استخدام الأسلوب العلمي في عمليات التقويم. \\
\hline .000 & $.410 * *$ & تُساهم الإدارة الإككترونية في تقييم إنجاز الأعمال وجودتها. \\
\hline .000 & $.460 * *$ & تُساهم الإدارة الإلكترونية في تحديث المعلومات والبيانات من خلال الرقابة \\
\hline .000 & $.502 * *$ & لعُساعد الإدارة الإكترونية في الكثف عن نقاط القوة لتعزيزها، ونقاط الضعف \\
\hline .000 & $.497 * *$ & تُساهم الإدارة الإلكترونية في تطبيق نظام رقابة منطور • \\
\hline .000 & $.576 * *$ & 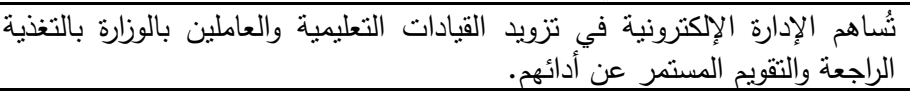 \\
\hline .000 & $.565 * *$ & ترسخ الإدارة الإلكترونية مبدأ المتابعة والرقابة الذاتية للمهمات الإدارية. \\
\hline .000 & $.460 * *$ & توفر الإدارة الإلكترونية طرق دقيقة لمتابعة ومراقبة الأعمال الإدارية. \\
\hline .000 & $.412 * *$ & تُساعد الإدارة الإلكترونية في توفير المتابعة والتقويم لمختلف المجالات الإدارية. \\
\hline .000 & $.552 * *$ & تُساهم الإدارة الإلكترونية في إيجاد وسائل متتوعة لتقييم العمل الإداري. \\
\hline
\end{tabular}


يتضح من الجدول السابق أن هناك ارتباط ذات دلالة إحصائية بين فقرات الرقابة والتقويم الإلكتروني والبعد الكلي للرقابة والتقويم الإلكتروني عند مستوى نقة (99.) تراوحت قيم الارتباط بين ( 384.، 662.) وهي ارتباطات جميعها معنوية ومن ثم فإن هذه الفقرات ممثلة بشكل قوى للمحور الرئيسى الرقابة والتقويم الإلكتروني وتقيس الغرض المربه التربه منه.

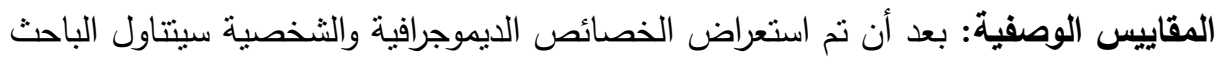

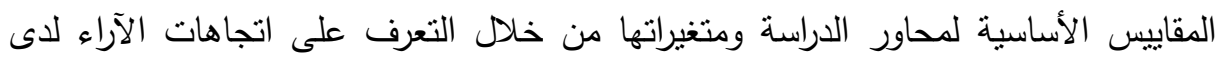
أفراد العينة بالنسبة لفقرات محاور الدراسة والأهمبة النسبية لها. أولًا : التخطيط الإكتروني: جدول رقم(^): المقاييس الوصفية لفقرات محور التخطيط الإلكتروني

\begin{tabular}{|c|c|c|c|c|}
\hline الأهمية & الاختلاف & 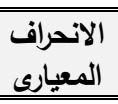 & المتوسط & التخطيط الإكتروني \\
\hline $75.81 \%$ & $16.64 \%$ & .631 & 3.79 & الأعباء الإدارية المختلفة. الإدارة الإكترونية في التخفيف من \\
\hline $73.52 \%$ & $17.49 \%$ & .643 & 3.68 & تلتعطل الإدارة الإلكترونية على تقليل كلفة إجراءات \\
\hline $74.48 \%$ & $17.27 \%$ & .643 & 3.72 & وُالمستجدات الإتخدام الإدارة الإلكترونية مواكبة المتغيرات \\
\hline $71.43 \%$ & $17.73 \%$ & .633 & 3.57 & تُُساهم الإدارة الإلكترونية في تطوير نظم التخطيط \\
\hline $74.86 \%$ & $16.16 \%$ & .605 & 3.74 & تُشناعد الإدارة الإلكترونية في إكساب الإداريين العديد \\
\hline $71.00 \%$ & $17.74 \%$ & .630 & 3.55 & تُشساهم الإدارة الإلكترونية في توفير الخطط الإدارية \\
\hline $75.62 \%$ & $15.55 \%$ & .588 & 3.78 & التخطويط المتخامل الإدارة الإلكترونية في تطبيق مفهوم \\
\hline $72.57 \%$ & $18.03 \%$ & .654 & 3.63 & 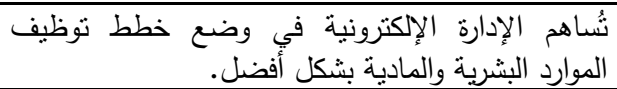 \\
\hline $76.19 \%$ & $17.11 \%$ & .652 & 3.81 & التُشطيط الإدارة الإلكترونية في إنشراك جميع الأطراف في \\
\hline $74.67 \%$ & $17.53 \%$ & .654 & 3.73 & التُشطيط. الإدارة الإلكترونية في الحد من مشكلات \\
\hline $74.06 \%$ & $11.14 \%$ & 0.412 & 3.703 & التخطيط الإلكتروني \\
\hline
\end{tabular}


ويوضح الجدول السابق بعض المقاييس الإحصائية الأساسية لفقرات محور التخطبط الإكتروني وأيضًا المحور الكلي ومن خلال قيم المتوسطات الحسابية نجد أن آراء أفراد العينة قد اتجهت جميعها نحو الموافقة لفقرات المحور حيث تراوحت قيم الوسط الحسابى بين (3.55 - 3.81) للفقرات (تُساهم الإدارة الإلكترونية في توفير الخطط الإدارية البديلة عند الحاجة، تُساهم الإدارة الإلكترونية في إنرالك جميع الأطراف في التخطبط الإستراتيجي) كما أوضحت الإنت

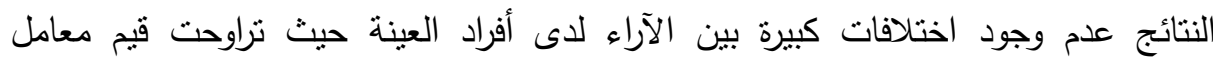
الاختلاف بين (15.55 - 18.03) كما نراوحت قيم الأهمية النسبية بين (71.00\%، .$(76.19 \%$

أما على مستوى المحور الكلي (التخطيط الإكتروني) فقد نبين أن متوسط آراء أفراد العينة بلغ (3.70) بانحراف معيارى يساوى (412.) كما أوضحت النتائج عدم وجود اختلافات

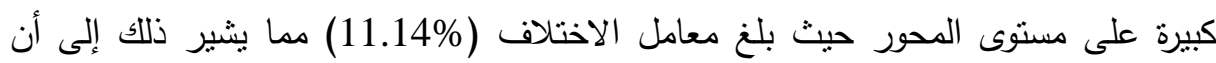
هنآك اتفاق واجماع بين آراء أفراد العينة بالموافقة على أهمية محور التخطيط الإكتروني

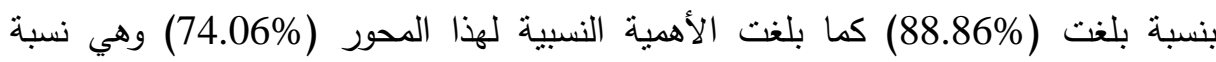
جيدة. 
سعد محمد عوض المطيري

ثُانبًا: التنظيِ الإكتروني: جدول رقم(9): المقاييس الوصفية لفقرات محور التتظيم الإلكتروني

\begin{tabular}{|c|c|c|c|c|}
\hline 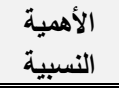 & الاختلاف معامل & الانحراف المعيارى & سنو & التنظيم الإكتروني \\
\hline $72.19 \%$ & $16.52 \%$ & .596 & 3.61 & ومكان. الإدارة الإلكترونية في الحصول على المعلومات في أي وقت \\
\hline $73.14 \%$ & $18.12 \%$ & .663 & 3.66 & الأطراف الإدارة الإلكترونية في توفير نظام أرشفة إلكترونية لمختلف \\
\hline $73.90 \%$ & $16.83 \%$ & .622 & 3.70 & تُساهم الإدارة الإلكترونية في توفير الوقت والمال والجهد. \\
\hline $73.52 \%$ & $17.49 \%$ & .643 & 3.68 & المعاملات. الإدارة الإكترونية عناء الانتقال عبر الإدارات لإنجاز \\
\hline $72.57 \%$ & $15.41 \%$ & .559 & 3.63 & تُساهم الإدارة الإككترونية في تتظيم عملية تسجيل المواد الدراسية. \\
\hline $79.43 \%$ & $18.30 \%$ & .727 & 3.97 & الإدارية. الإدارة الإلكترونية على تسهيل عملية التوجيه لمختلف الأطراف \\
\hline $79.62 \%$ & $18.43 \%$ & .734 & 3.98 & الإدارية. الإدارة الإكترونية في تأمين التواصل بين مختلف العناصر \\
\hline $73.52 \%$ & $18.28 \%$ & .672 & 3.68 & 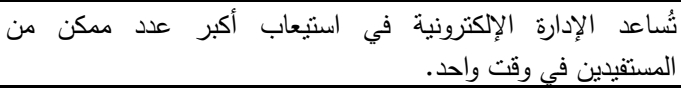 \\
\hline $70.29 \%$ & $16.79 \%$ & .590 & 3.51 & تساعد الإدارة الإلكترونية في كسر حاجز الروتين في إجراء \\
\hline $73.52 \%$ & $19.05 \%$ & .700 & 3.68 & ثُساهم الإدارة الإلكترونية في رفع مستوى تطبيق إدارة شؤون الطلبة. \\
\hline $75.43 \%$ & $18.11 \%$ & .683 & 3.77 & الدراسية. الإدارة الإلكترونية في توفير فرص الإطلاع على جداول المواد \\
\hline $72.38 \%$ & $17.72 \%$ & .641 & 3.62 & تإكترونيًا. الإدارة الإلكترونية في تتظيم اجتماعات القيادات التعليمية \\
\hline $75.43 \%$ & $16.14 \%$ & .609 & 3.77 & تساهم الإدارة الإلكترونية في إيجاد بيئة تنظيمية تتسم بالدقة. \\
\hline $71.05 \%$ & $17.01 \%$ & .604 & 3.55 & تساعد الإدارة الإلكترونية في توفير مبدأ الخصوصية للى مختلف \\
\hline $74.29 \%$ & $17.79 \%$ & .661 & 3.71 & إلكترونيًا. الإدارة الإلكترونية في تحقيق التواصل مع أولياء أمور الطلاب \\
\hline $72.95 \%$ & $14.22 \%$ & .519 & 3.65 & داخل النظام الإلكتروني بالوزارة. \\
\hline $73.95 \%$ & $9.78 \%$ & 0.362 & $\begin{array}{c}3.69 \\
8\end{array}$ & التنظيم الإلكتروني \\
\hline
\end{tabular}


ويوضح الجدول السابق بعض المقاييس الإحصائية الأساسية لفقرات محور التنظيم الإككتروني وأيضًا المحور الكلي ومن خلال قيم المتوسطات الحسابية نجد أن آراء أفراد العينة قد اتجهت جميعها نحو الموافقة لفقرات المحور حيث تراوحت قيم الوسط الحسابى بين (3.51 - 3.98) للفقرات (تساعد الإدارة الإكترونية في كسر حاجز الروتين في إجراء المعاملات

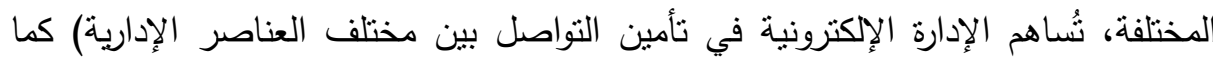
أوضحت النتائج عدم وجود اختلافات كبيرة بين الآراء لدى أفراد العينة حيث تراوحت قيت لإدين معامل الاختلاف بين (14.22 - 19.05) كما تراوحت قيم الأهمية النسبية بين (70.29\% ، .$(79.62 \%$

أما على مستوى المحور الكلي (التتظيم الإلكتروني) فقد تبين أن متوسط آراء أفراد العينة بلغ (3.69) بانحراف معيارى يساوى (362.) كما أوضحت النتائج عدم وجود اختلافات كبيرة على مستوى المحور حيث بلغ معامل الاختلاف (9.78\%) مما يشير ذلك إلى أن هناك اتفاق

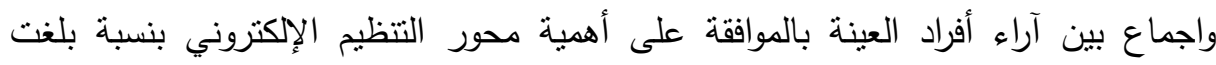
(90.22\%) كما بلغت الأهمية النسبية لهذا المحور (73.95\%) وهي نسبة جيدة. 
سعد محمد عوض المطيري

ثُالثًا: التنقيذ الإكتروني: جدول رقم( • 1): المقاييس الوصفية لفقرات محور التنفيذ الإلكتروني

\begin{tabular}{|c|c|c|c|c|}
\hline 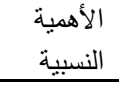 & 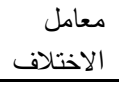 & 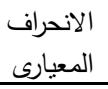 & المتوسط & التنفيذ الإكتروني \\
\hline $74.10 \%$ & $13.46 \%$ & .499 & 3.70 & 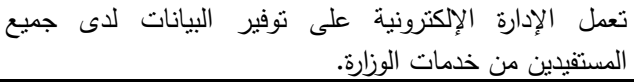 \\
\hline $72.76 \%$ & $17.52 \%$ & .637 & 3.64 & فُساعد الإدارة الإلكترونية في التخلص من النظام البيروقراطي \\
\hline $74.48 \%$ & $14.66 \%$ & .546 & 3.72 & والمجتمعية. الإدارة الإلكترونية في تأدية الوزارة لوظيفتها التربوية \\
\hline $72.38 \%$ & $18.92 \%$ & .685 & 3.62 & 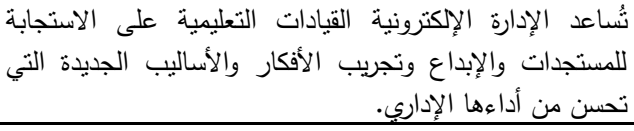 \\
\hline $72.00 \%$ & $17.05 \%$ & .614 & 3.60 & تُسهولة الإدارة الإلكترونية في تتفيذ العديد من الخطط الإدارية \\
\hline $72.76 \%$ & $16.67 \%$ & .606 & 3.64 & تعليمل الإدارة الإلكترونية على تقديم المعلومات بشكل دقيق \\
\hline $70.67 \%$ & $17.14 \%$ & .606 & 3.53 & 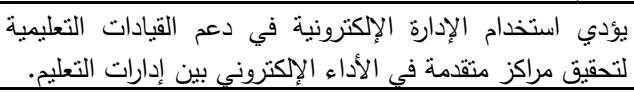 \\
\hline $74.48 \%$ & $17.66 \%$ & .658 & 3.72 & تساعد الإدارة الإكترونية في الاستغلال الأمثل ل لهصادر \\
\hline $76.38 \%$ & $15.74 \%$ & .601 & 3.82 & 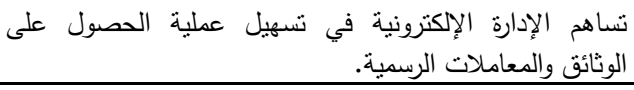 \\
\hline $73.14 \%$ & $18.12 \%$ & .663 & 3.66 & التُعاملات الإدارة الإلكترونية في تحسين ألأدياء الإداري في جميع \\
\hline $74.48 \%$ & $16.86 \%$ & .628 & 3.72 & في إنهاء الإدارة الإلكترونية على الحد من تأثير العلاقات الثخصية \\
\hline $73.90 \%$ & $18.81 \%$ & .695 & 3.70 & 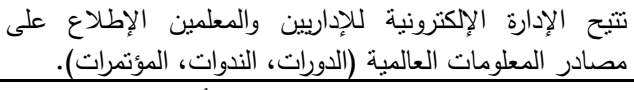 \\
\hline $73.90 \%$ & $17.65 \%$ & .652 & 3.70 & تنداعد الإدارة الإكترونية في تحقيق مبدأ الثفافية في تقديم \\
\hline $79.24 \%$ & $15.62 \%$ & .619 & 3.96 & الخدمات. الإدارة الإلكترونية الكثير من المرونة والسرعة في تقيم \\
\hline $79.81 \%$ & $17.20 \%$ & .686 & 3.99 & 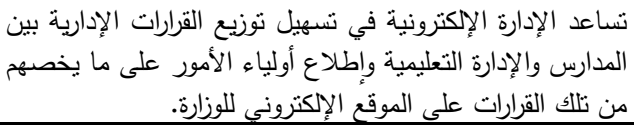 \\
\hline $78.67 \%$ & $16.64 \%$ & .654 & 3.93 & تساهم الإدارة الإلكترونية في سرعة تتفيذ القرارات الإدارية. \\
\hline $74.57 \%$ & $9.25 \%$ & 0.345 & 3.729 & التتفيذ الإكتروني \\
\hline
\end{tabular}

المجلد الاربعون، الجزء الثالث، ديسمبر Y V r T 
ويوضح الجدول السابق بعض المقاييس الإحصائية الأساسية لفقرات محور التتفيذ الإلكتروني وأيضًا المحور الكلي ومن خلال قيم المتوسطات الحسابية نجد أن آراء أفراد العينة قد اتجهت جميعها نحو الموافقة لفقرات المحور حيث تراوحت قيم الوسط الحسابى بين (3.53

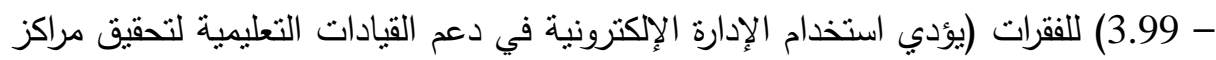

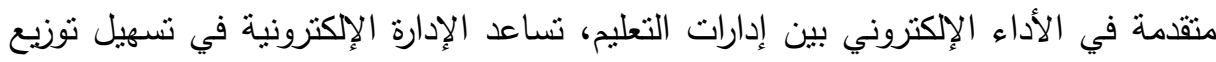

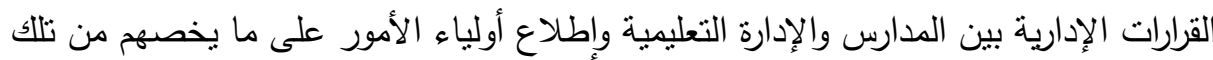

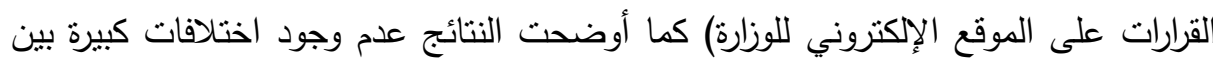
الآراء لاى أفراد العينة حيث تراوحت قيم معامل الاختلاف بين (13.46 - 18.92) كما تراوحت قيم الأهية النسبية بين (70.67\% ، 79.81\%). أما على مستوى المحور الكلي (التنفيذ الإكتروني) فقد تنين أن متوسط آراء أفراد العينة بلغ (3.73) بانحراف معيارى يساوى (345.) كما أوضحت النتائج عدم وجود اختلافات كبيرة على مستوى المحور حيث بلغ معامل الاختلاف (9.25\%) مما يشير ذلك إلى أن هناك اتفاق

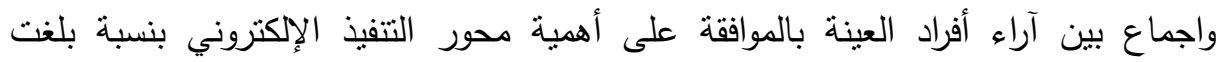
(90.75\%) كما بلغت الأهمية النسبية لهذا المحور (74.57\%) وهي نسبة جيدة. 
رايعًا: الرقابة والتقويم الإكتروني: جدول رقم(1 1 ): المقاييس الوصفية لفقرات محور الرقابة والتقويم الإلكتروني

\begin{tabular}{|c|c|c|c|c|}
\hline الأهمية - النسبية & الاختلاف & الانحراف & المتوسط & الرقابة والتقويم الإكتروني \\
\hline $80.38 \%$ & $12.90 \%$ & 19 & 4.02 & تُساهم الإدارة الإلكترونية في تطبيق نظام تدقيق مالي منطور . \\
\hline $79.81 \%$ & $14.95 \%$ & .596 & 3.99 & شُساعد الإدارة الإلكترونية في متابعة الخطط والأعمال اليومية. \\
\hline $81.14 \%$ & $13.16 \%$ & .534 & 4.06 & تزود الإدارة الإلكترونية القيادات التعليمية بالتقارير والبيانات \\
\hline $73.52 \%$ & $17.49 \%$ & .643 & 3.68 & والتُلهم الإدارة الإلكترونية في توفير نظام رقابي إلكتروني وفقًا للوائح \\
\hline $74.48 \%$ & $17.27 \%$ & .643 & 3.72 & التُقاهم الإدارة الإلكترونية في استخدام الأسلوب العلمي في عمليات \\
\hline $71.24 \%$ & $17.81 \%$ & .634 & 3.56 & تُساهم الإدارة الإلكترونية في تقييم إنجاز الأعمال وجودتها. \\
\hline $72.19 \%$ & $16.52 \%$ & .596 & 3.61 & الرقابة والإدارة الإككترونية في تحديث المعلومات والبيانات من خلا \\
\hline $73.14 \%$ & $18.12 \%$ & .663 & 3.66 & 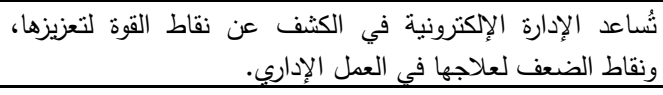 \\
\hline $73.71 \%$ & $16.96 \%$ & .625 & 3.69 & تُساهم الإدارة الإلكترونية في تطبيق نظام رقابة منطور. \\
\hline $72.76 \%$ & $17.52 \%$ & .637 & 3.64 & 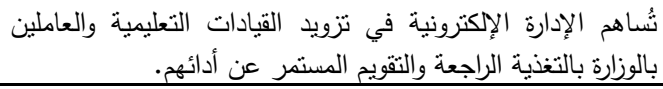 \\
\hline $75.05 \%$ & $16.44 \%$ & .617 & 3.75 & ترسخخ الإدارة الإلكترونية مبدأ المتابعة والرقابة الذاتية للمهمات \\
\hline $70.86 \%$ & $17.07 \%$ & .605 & 3.54 & الإدارية. الإدارة الإكترونية طرق دقيقة لمتابعة ومراقبة الأعمال \\
\hline $75.43 \%$ & $15.71 \%$ & .593 & 3.77 & المجاعد الإدارة الإلكترونية في توفير المتابعة والتقويم لمختلف \\
\hline $72.76 \%$ & $17.93 \%$ & .652 & 3.64 & الإداريم الإدارة الإلكترونية في إيجاد وسائل منتوعة لنقييم العمل \\
\hline $74.75 \%$ & $8.73 \%$ & 0.326 & 3.737 & الرقابة والثقويم الإلكتروني \\
\hline
\end{tabular}

ويوضح الجدول السابق بعض المقاييس الإحصائية الأساسية لفقرات محور الرقابة

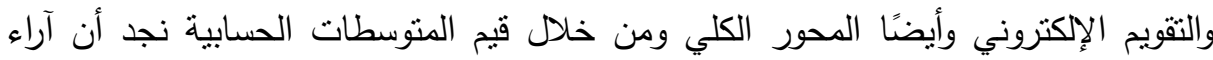
أفراد العينة قد اتجهت جميعها نحو الموافقة لفقرات المحور حيث تراوحت قيم الوسط الحسابى بين (3.54 - 4.06) للفقرات (توفر الإدارة الإككترونية طرق دقيقة لمتابعة ومراقبة الأعمال الإدارية، تزود الإدارة الإلكترونية القيادات التعليمية بالتقارير والبيانات الإحصائية) كما لإدانه 
أوضحت النتائج عدم وجود اختلافات كبيرة بين الآراء لدى أفراد العينة حيث تراوحت قيم معامل الاختلاف بين (12.90 - 18.12) كما تراوحت قيم الأهمية النسبية بين (70.86\%،

.$(81.14 \%$

أما على مستوى المحور الكلي (الرقابة والتقويم الإلكتروني) فقد تبين أن متوسط آراء

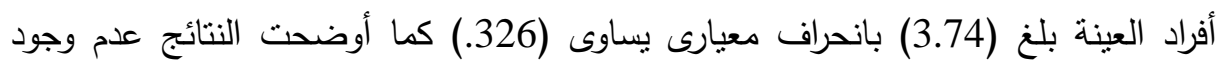

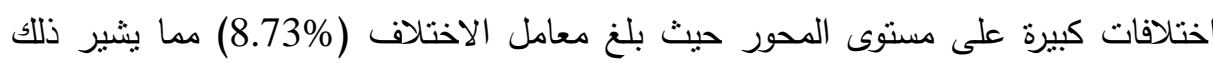

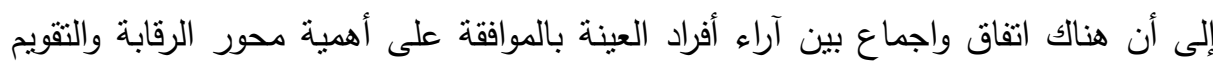
الإكتروني بنسبة بلغت (91.27\%) كما بلغت الأهمية النسبية لهذا المحور (74.75\%) وهي لهي نسبة جيدة.

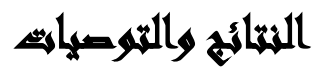

ينتاول هذا الجزء أهم النتائج التي تم التوصل إليها بعد إجراء الدراسة الميدانية، وبناءً

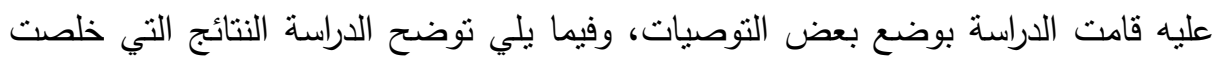
إليها على النحو التالي : النها:

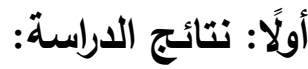

• أظهرت النتائج اتجاه استجابات أفراد العينة نحو الموافقة على أهمية محور التخطبط الإلكتروني إلى جانب ذللك تبين وجود اختلافات فى الآراء بنسبة بلغت 11.14\% وهي أقل من النسبة المقبولة كما بلغت الأهمية النسبية لمحور التخطيط الإكتروني وهي نسبة جيدة. • أظهرت النتائج اتجاه استجابات أفراد العينة نحو الموافقة على أهمية محور التتظيم

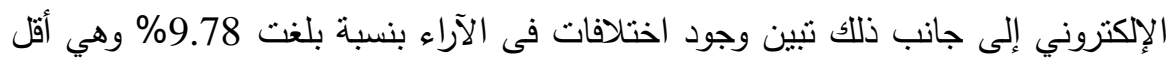

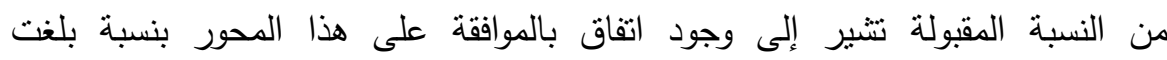

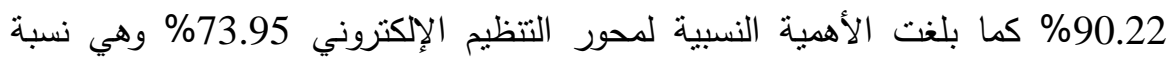


• أظهرت النتائج اتجاه استجابات أفراد العينة نحو الموافقة على أهمية محور التتفيذ

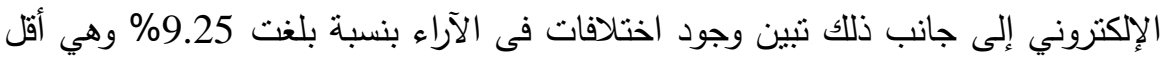

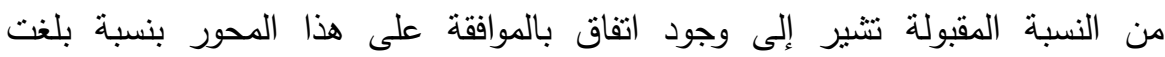

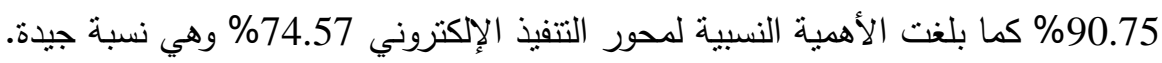
أظهرت النتائج اتجاه استجابات أفراد العينة نحو الموافقة على أهمية محور الرقابة والتقويم الإكتروني إلى جانب ذلك تبين وجود اختلافات فى الآراء بنسبة بلغت 8.73\% وهي أقل الته

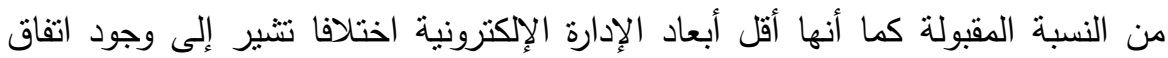
بالموافقة على هذا المحور بنسبة بلغت 91.27\% كما بلغت الأهمية النسبية لمحور الرقابة

$$
\text { والتقويم الإلكتروني 74.75\% وهي نسبة جيدة. }
$$

• يُساعد تطبيق الإدارة الإلكترونية في المدارس بدولة الكويت إلى توفير الخطط الإدارية

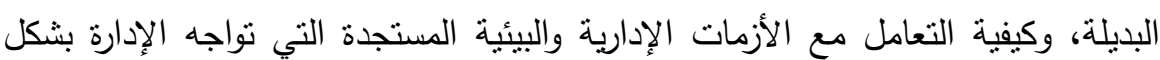

إن استخدام الإدارة الإلكترونية يساعد على التخفيف من الأعباء الإدارية المختلفة في

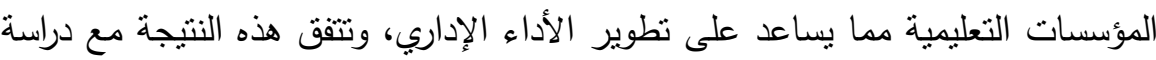

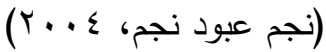

ثُساعد الإدارة الإلكترونية في إكساب الإداريين العديد من الخبرات الإدارية المنطورة والتي (Dimitriades, تتواكب مع منطلبات العصر، وتحدياته، وتتفق هذه النتيجة مع دراسة (2005 حيث إن المؤسسة الحديثة تتصف بتوجيه الجهود نحو تدريب وتتمية الموارد البشرية من الإداريين بما يواكب التطورات والتقنية العلمية، وما يتيح المجال للعاملين لاكتساب المهارات والخبرات التي تحسن من أدائهم.

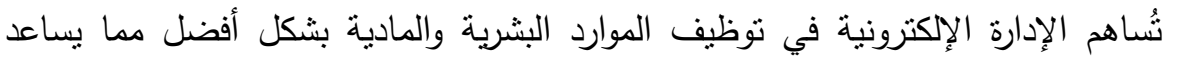
على تطوير الأداء الإداري للمدرسة. تلعب الإدارة الإلكترونية دورًا هام في إنجاز الأعمال في وقت أقل منها في الإدارة النمطية، كما توفر على العاملين والمستقيدين من الخدمة عناء الانتقال عبر الإدارات 
لإنجاز معاملتهم، وما يشعرهم بالراحة واللسرعة والدقة في الحصول على ما يحتاجونه من

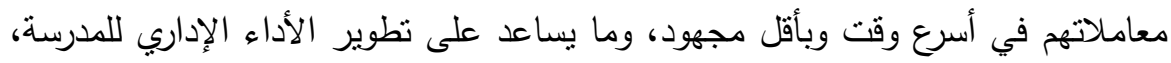

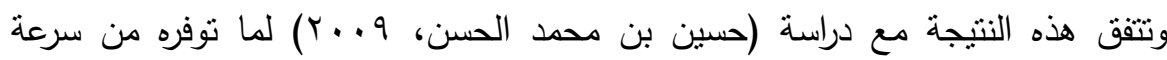
عمليات الحفظ والاسترجاع، وتوفير الجهد في التتقل بين الأقسام المختلفة للبحث عن بن

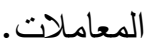

• يساعد استخدام الإدارة الإكترونية القيادات التعليمية التميز بالدقة في إنجاز المعاملات الخاصة بالمستفيدين من الخدمة لحصولهم على الخدمة المطلوبة من قبلهم بسرعة ودقة، وموثقة إلكترونيًا بتاريخ بتوقيت ارسال الطلب وتاريخه، وتوقيت وتاريخ إنجاز المعاملة وإرساله إلى المستقيد مما يحسن الأداء الإداري للمدرسة.

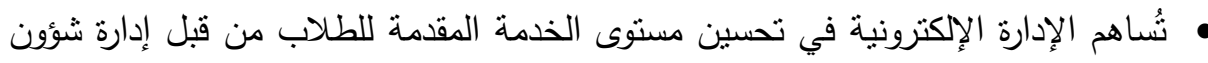
الطلاب لاعتمادها على العمل القائم على التنظيم الإلكتروني الذي يسهل فئل عملية الإدخال والحفظ والتخزين والاسترجاع في بيئة إلكترونية مؤسسة وسريعة ودقيقة ، مما يساعد في لهي

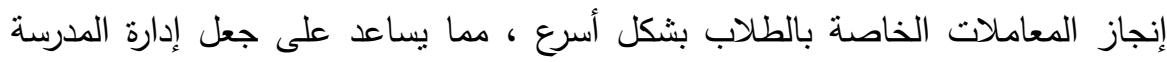

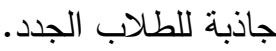
نساعد الإدارة الإككترونية في كسر حاجز الروتين في إجراء المعاملات المختلفة.

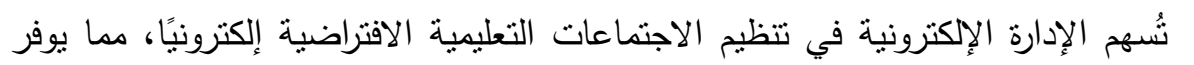

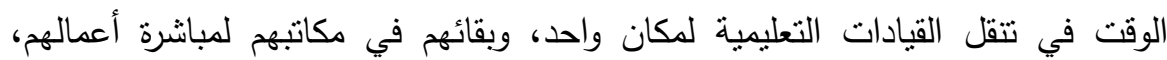
والمشاركة في الاجتماعات الافتراضية عبر السكايبي، والفيديو، كونفرانس، بالإضافة إلى ولى

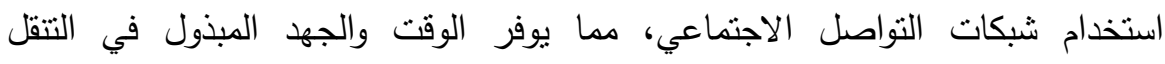
والاتظظار لأعضاء مجلس الإدارة، وتعطيل أعمالهم لحضور المجالس التعليمية، وما يسهل عملية الاجتماعات في أي وقت لمواجهة المشكلات اليومية في الوزارة.

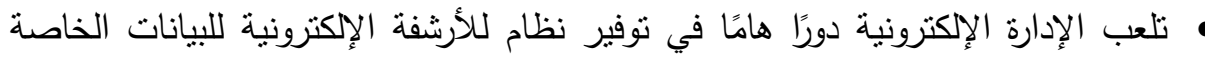

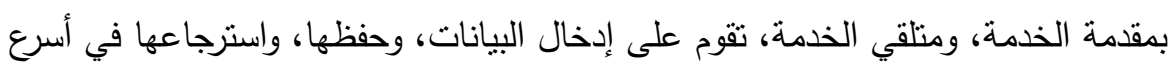
وقت، وبشكل منظم في بيئية إلكترونية، وتتفق هذه النتيجة مع دراسة (محد الصيرفي، 


\section{ثانيًا: توصيات ومقترحات الاراسة:}

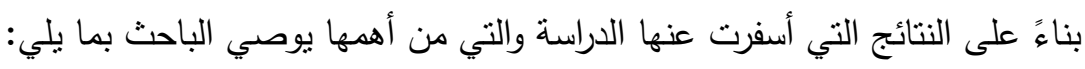

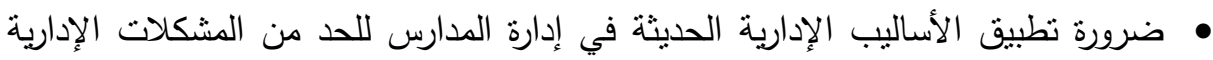

$$
\text { وتطوير الأداء الإداري للقيادات التعليمية. }
$$

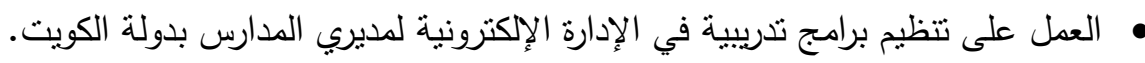

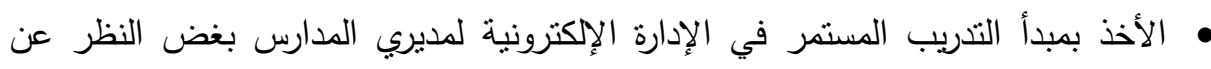

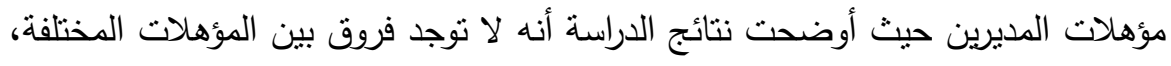

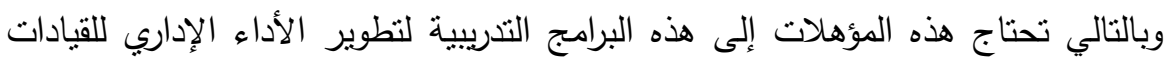

$$
\text { التعليمية في الددارس. }
$$

إجراء المزيد من الدراسات حول الإدارة الإلكترونية في الددارس للتعرف على مدى تطبيقها للإدارة الإلكترونية، لتطوير الأداء الإداري بالدارس.

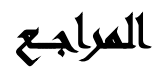

عونية طالب أبو سنينة: الإدارة الإكترونية لمدارس التعليم قبل الجامعي في المملكة الأردنية

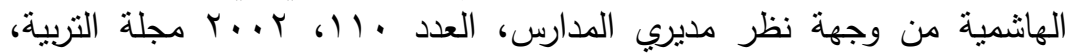

$$
\text { جامعة الأزهر، القاهرة. }
$$

خليفة مصطفى أبو عاثشور \& ديانا جميل النمري: مستوى تطبيق الإدارة الإكترونية في

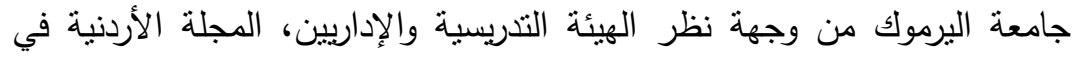

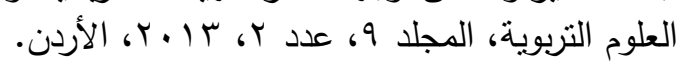

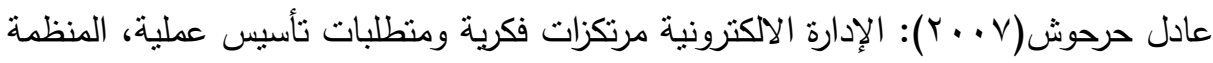

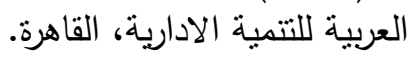

محمد الحيلة( ( . ب): التكنولوجيا التعليمية والمعلوماتية، العين، الإمارات العربية المتحدة. محمد جمال الدين درويش( (... ب): التخطيط للمجتمع المعلوماتي، كراسات علمية - سلسلة غير دورية، المكتبة الأكاديمية، القاهرة. 
رأفت رضوان: الإدارة الإلكترونية، ورقة عمل مقدمة إلى الملتقى الإداري الثاني للجمعية

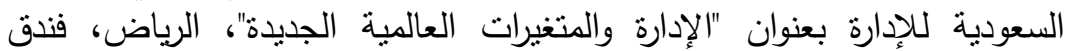

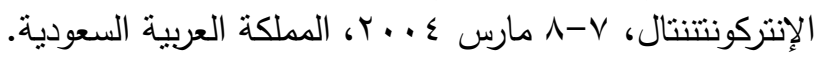

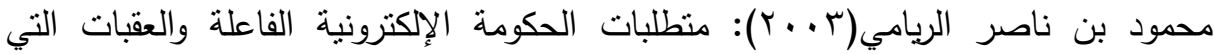
تواجهها، بحث مقدم لندوة الحكومة الإلكترونية في مسقط، عمان.

ناصر بن سعود الريس(^ . . r) : واقع استخدام الحاسب الآلي والإنترنت في الإدارة المدرسية،

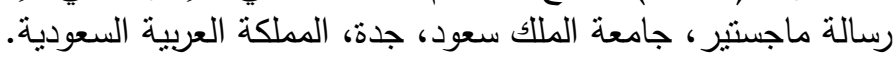

علاء السالمي \& خالد السليطي(^ . . r) : الإدارة الإلكترونية، دار وائل للنشر والتوزيع، عمان.

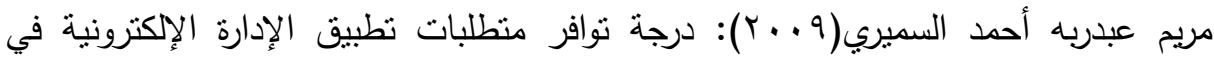

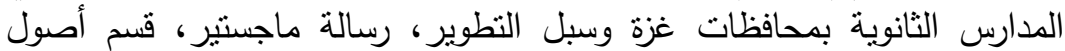

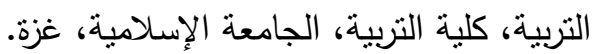

مصطفى أحمد سيد( ( . ب): المدير وتحديات العولمة، دار النهضة العربية، القاهرة. نجوى الثناوي: التحول نحو المنظمة الإلكترونية في الوطن العربي-التحديات والمتطلبات،

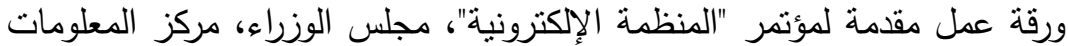

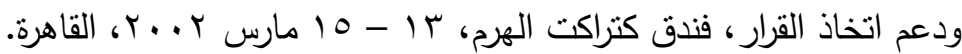

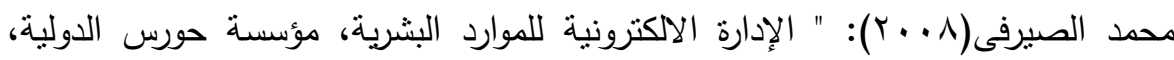

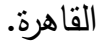

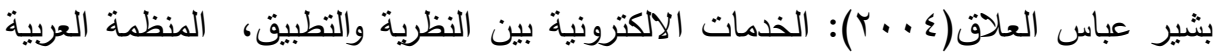

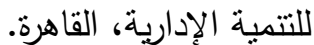

نائل عبد الحفيظ العوامله: الحكومة الإكترونية ومستقبل الإدارة العامة، مجلة دراسات، مجلد الإدردية

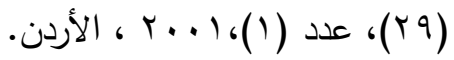

أحمد بن علي غنيم: دور الإدارة الإكترونية في تطوير العمل الإداري ومعوقات استخدامها في الإني

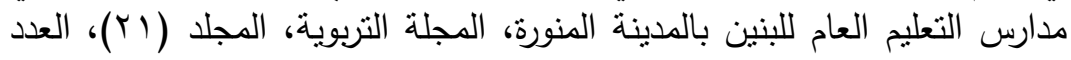

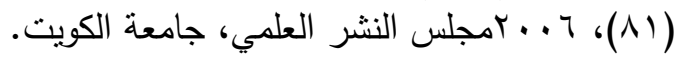

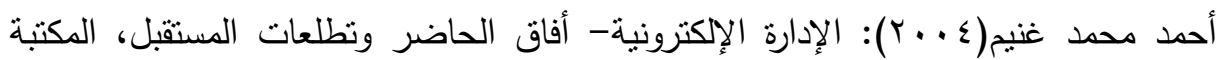

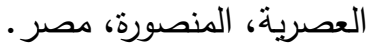




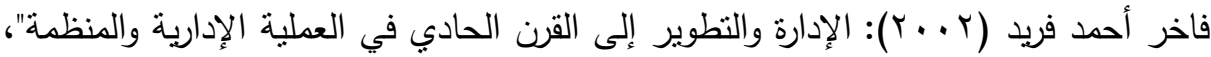
مطابع الثرطة للطباعة والنشر والتوزيع، التاهرة التهري

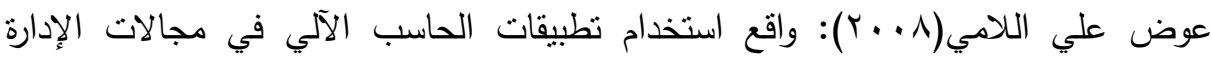

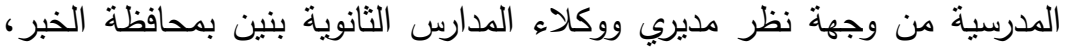
رسالة ماجستير ، كلية التربية، الجامعة الخليجية، مملكة البحرين.

عبد الحمبد محمد محمد \& اسامة محمود قرني: متطلبات تطبيق الإدارة الإكترونية

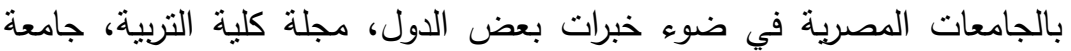

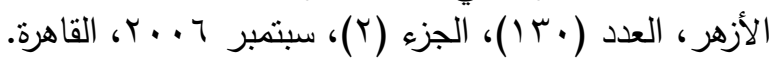

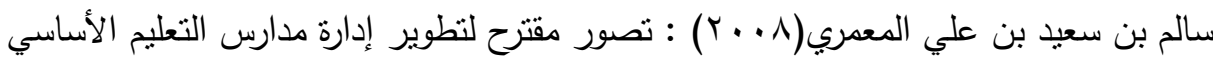

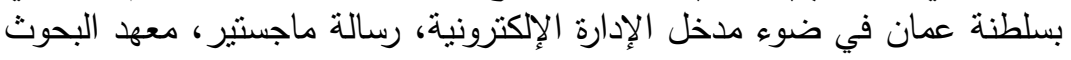
العربية، جامعة الدول العربية، القاهرة.

عبد الله عبد العزيز الموسى: التعليم الإلكتروني-مفهومه وخصائصه وفوائده وعوائقه، ورقة

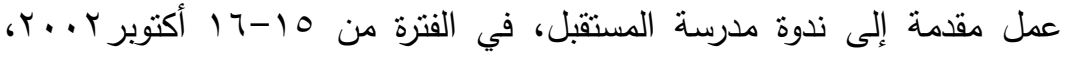
الرياض، جامعة الملك سعود، المملكة العربية السعودية.

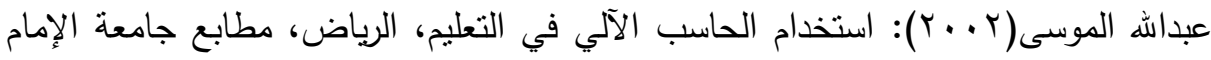
محمد بن سعود الإسلامية، المملكة العربية السعودية.

نجم عبود نجم(ع . . ץ): الإدارة الالكترونية الاستراتيجية والوظائف والمشكلات، دار المريخ،

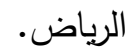

محمد نوفل: الحكومة الإككترونية بالمدينة العربية بين الطموحات والمحاذير ، ورقة عمل مقدمة في مؤتمر الحكومة الإلكترونية : الواقع والتحديات، المنعقد في مسقط بسلة بسلطنة عُمان

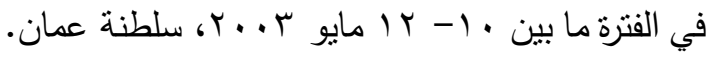

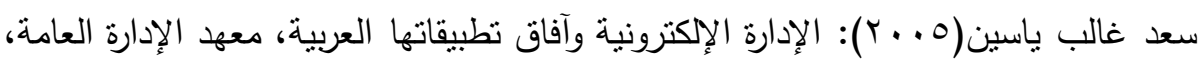
مركز البحوث، الرياض، المملكة العربية السعودية. 


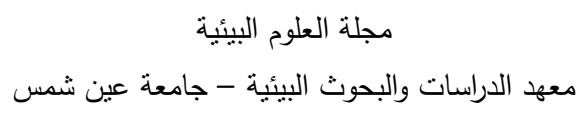

\title{
ROLE OF E-MANAGEMENT AS AN INPUT TO THE DEVELOPMENT OF EDUCATIONAL LEADERSHIP PERFORMANCE IN THE STATE OF KUWAIT
}

\author{
Saad Mohamed Awad Al-Mutairi \\ Ministry of Education, Kuwait
}

\begin{abstract}
aim the study was to identify role of e-management in developing performance of educational leaders in Kuwait, The study sample consisted of (70) educational leaders in the six governorates (AlFarwaniya, Al-Jahra, Ahmadi, Mubarak Al-Kabeer, Hawalli) in Kuwait, The study used descriptive analytical method.

\section{Results:}

- results showed differences of opinion at $11.14 \%$, which is less than the acceptable percentage. The relative importance of the e-planning axis was $74.06 \%$.

- results showed that there were differences of opinion at a rate of $9.78 \%$, which is less than the acceptable percentage indicating that there is agreement to approve this axis by $90.22 \%$ and the relative importance of the axis of electronic organization $73.95 \%$, which is good.

- results showed that there were differences of opinion at a rate of $9.25 \%$, which is lower than the acceptable percentage indicating that there is agreement to approve this axis by $90.75 \%$ and the relative importance of the e-implementation axis is $74.57 \%$ which is good.

- results showed differences of opinion at $8.73 \%$, which is less than the acceptable percentage. The lowest dimensions of electronic management are differences indicating that there is agreement to approve this axis by $91.27 \%$. The relative importance of the electronic monitoring and evaluation axis is $74.75 \%$.
\end{abstract}

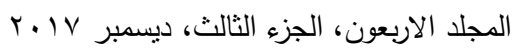


سعد محمد عوض المطيري

Keywords: Role - E-Management - Performance Development Educational Leadership 